\title{
PHEOCHROMOCYTOMA DURING CHILDHOOD - A CASE REPORT
}

\author{
L. Marinov \\ Department of Pediatrics \\ Medical University "Prof. Dr Paraskev Stoyanov"-Varna, Bulgaria
}

\section{SUMMARY}

Pheochromocytoma is a rare tumor during childhood, originating from the chromafine tissue. According to literature its frequency is approximately $1 / 100000$. Its clinical manifestation is with signs of catecholamine excess: hypertension, heartbeat, headache, sweating, nausea, vomiting, trembling, weakness, irritation, abdominal and chest pain, dyspnea, red warm face, constipation, polyuria, polydipsia. These symptoms can be observed every day in severe disease or rarely. The clinical manifestation can be variable and assembling many other diseases, so the pheochromocytoma is called "the Great imitator". We are presenting a case - a 15 years old girl, hospitalized for hypertonic crisis. After the clinical, paraclinical investigations and image test was proved that this was a pheochromocytoma. The surgical intervention was held in planned order. During the following months the blood pressure became normal and the hypertension treatment was ceased. The possibility of relapses of the tumor necessitates the following of the child for the next years.

Key words: Pheochromocitoma, childhood, hypertension

Pheochromocytoma is a rare tumor during childhood, originating from the chromaffine tissue. According to literature its frequency is approximately $1 / 100000.2$ cases of pheochromocytoma in children are reported in the Bulgarian pediatric literature $(1,2)$. Its clinical manifestation is with signs of catecholamine excess: hypertension, heartbeat, headache, sweating, nausea, vomiting, trembling, weakness, irritation, abdominal and chest pain, dyspnea, red warm face, constipation, polyuria, polydipsia. These symptoms can be observed every day in severe disease or rarely. The clinical manifestation can be variable and assembling many other diseases, so the pheochromocytoma is called "the Great imitator".

We had the possibility to observe a case of pheochromocytoma in 15 years old girl, hospitalized in the clinic urgently because of hypertonic crisis.

A clinical case: M. K. G. 15 years old of second normal pregnancy and birth, born on time with weight $3600 \mathrm{~g}$, with normal after birth period, with normal physical and nerve-psychic development.
The child had a familial history of Diabetes mellitus II type. At the age of 10 , she was operated for cyst of the esophagus.

For 1 year before hospitalization she complained of headache, dizziness and sense of "heartbeat". Because of the headache she was examined by ophthalmologist lowered visus $0,9-0,8$. The found changes on the eyes were interpreted as signs of neurouveitis. A treatment was started with Diprofos locally and Prednisolon tabl, Geritamin. The blood pressure was not measured!!!

She was directed for hospitalization urgently with signs of hypertonic crisis. The measured values of the blood pressure were 200/140 mm Hg.

She was admitted in damaged condition, with slightly changed consciousness, afebrile. Skin - pale, surgical cicatrix in the neck region. Reduced hypodermic fat tissue. Mucoses - pale pink, rich vascularizated conjunctives. Head and neck - normal. Astenic chest, vesicular breathing. Se

Cardio-vascular system - no vosur and fremisman, rhythmic tachycardic heart beat, increased II tone on Erb and right bases, protomesosystolic $2 / 6$ noise with p.max on Erb and right bases, with limited propagation to the carotid vessels, fr. 126/min., and pulse - well filled on all extremities. BP 180/120 mm Hg.

Abdomen - soft, no organomegaly. Urinary system no pathological changes, Sucusio renalis - negative. Bone and muscular system - no pathological changes

Laboratory tests: SSE-10 mm, Нв-140-160g/1, Leuc. 11,5-16,5.10 $9 / 1$, Leukocyte count - normal, ASAT, ALAT, blood glucose, urea, creatinin, uric acid - normal; total protein - $79 \mathrm{~g} / 1$, normal distribution of the protein fractions, ANA-negative, CIK 10E, LE cells - neg., T3, T4, TTHnormal, blood-sugar profile and OGTT - normal; urine analysis - alb - neg., sediment - normal. Lipid profile - total cholesterol - 7,22; TG-1,11; HDL-c - 1,6 mmol/1; LDL-c - 3,6 $\mathrm{mmol} / \mathrm{l}$.

Consultation with Ophthalmologist: papilla on the level of retina, vessels with increased arterial reflex bilaterally. In the left macula there was a disturbed macula star. Hemorrhages below left papilla. Possibly this is retinopathia hypertonica, II-degree by Keith, Wagener, Barker. In DD plan - neurouveitis with involvement of vessels - vasculitis. 
Second consultation with ophthalmologist: no changes in the eye bottom, resorption of the left haemorrhages.

Chest X-ray: heart and lungs - no changes

ECG: sin. rhythm, indifferent electric axis, repolarisation disorders against left ventricle.

EchoCG: Normal heart anatomy, enlarged LVMM, with ILVMM - 78,3 g/ $/ \mathrm{m}^{2}$ ( norm $76 \mathrm{~g} / \mathrm{m}^{2}$ ).

Ultrasound sonography: in the first test there were no pathological changes.

On the second ultrasound between the left kidney and spleen there was a tumor formation with homogenous content, with round shape and sharp borders with size 3,9/ $4,5 \mathrm{~cm}$.

Renovasography: after contrasting of the abdominal aorta there are no stenotic regions and asymmetry of both renal arteries. After contrasting of the left renal artery in the pool of the suprarenal artery there is a round area with pathologic vessel net and almost homogenous tumor spot (Fig.1, Fig.2). There are no pathological changes in right.

CT scan: tumor lesion engaging the left suprarenal gland with size $4 / 5 \mathrm{~cm}$. After intra venous contrast, the mass increased its absorption coefficients. The lesion compresses and dislocates the tail of the pancreas and arteria lienalis. The left renal vein looks dilated and can not be contrasted homogenous at all levels, which can be because of engagement of the described lesion and thrombosis. There are no positive foci in liver, spleen, pancreas and gall bladder, as well as enlarged lymph nodes. Conclusion: Tu formation of left suprarenal gland, most likely to be Pheochromocytoma (Fig.3).

\section{TREATMENT:}

Beta blockers, diuretics, symptomatic medications.

After the start of the antihypertensive combination, the blood pressure showed slight tendency of lowering, but was stable at levels of 140-150 mm Hg for SBP and 100-110 $\mathrm{mm} \mathrm{Hg}$ for DBP. The patient had 2 incidents with worsening of the headache and vomiting with increase of the blood pressure to $180 / 120 \mathrm{~mm} \mathrm{Hg}$ and tachycardia.

After consultation with urologist, the child was transferred to the clinic of Urology for surgery.

From the operative protocol: the surgical approach is with left lumbectomy and resection of 12th rib. The kidney is reached. In the suprarenal region there is a tumor formation - with round shape, capsule and rich vascularization with size $4 / 6 \mathrm{sm}$. The tumor formation is rejected. The material is sent for histological tests.

Histological result: Suprarenal tumor - Pheochromocytoma, with no infiltration of the capsule.

Control abdominal ultrasound: no pathological changes.

Control CT - scan: in the suprarenal region, there is a linear structure which is probably a result of postoperative adhesion on the bases of hemorrhage.

In the post-operative period the antihypertensive treatment continued. After the normalization of the blood pressure the treatment was stopped. After the final stop of the antihypertensive treatment her blood pressure is stable at $100-110 \mathrm{~mm} \mathrm{Hg}$ for SBP and 70-80 $\mathrm{mm} \mathrm{Hg}$ for DBP.

After more than one year of follow up, the blood pressure is in the normal ranges without antihypertensive treatment.

\section{DISCUSSION}

In the reported case there were two possible diagnoses, which manifestation is with high - grade and resistant to treatment hytertension. These are renovasal hypertension or pheochromocytoma. The renovasal hypertension is more frequent than the pheochromocytoma. It represents over $10 \%$ of the cases of symptomatic arterial hypertension during childhood and occurs in conditions of worsened blood stream to the kidney or to part of it. (8).

To the diagnoses, in our case, pointed the severe hypertension, the periods of increase of the blood pressure, accompanied with severe headache and vomiting. Similar clinical manifestation is described, by American authors, in 9 years old girl, hospitalized for severe headache and increased levels of blood pressure. (7). On the accomplished renovasography there were no stenotic regions and asymmetry of the renal arteria, which excluded the possibility to be renovasal hypertension. The additional findings in the pool of the left suprarenal arteria, where was found a round zone with pathological vessel net and almost homogenouse tumor bed, made obligatory the making of CT - scan. The result showed tumor formation of the left suprarenal gland, possibly pheochromocytoma.

Pheochromocytoma has a significantly smaller part in the etiology of symptomatic arterial hypertension $0,5-1 \%$ $(3,10)$.

Pheochromocytoma, a tumor of neuroendocrine origin, is a rare tumor found in children and adults and is a cause of sympptomatic hypertension. Pheochromocytoma is a catecholamine-secreting tumor that arises from chromaffin cells of the sympathetic nervous system (adrenal medulla and sympathetic chain); however, the tumor may develop anywhere in the body. These tumors release catecholamines into the circulation, causing significant hypertension. In children, pheochromocytoma is more frequently associated with other familial syndromes, such as neurofibromatosis, von Hippel-Lindau disease, tuberos sclerosis, and Sturge-Weber syndrome, and as a component of multiple endocrine neoplasia (MEN) syndromes (MEN 2A, MEN 2B). Familial cases are often bilateral or multicentric within an individual adrenal gland. Adrenal pheochromocytomas are most often found on the right side and are sporadic, unilateral, and intra-adrenal. Approximately $6-10 \%$ of the tumors are malignant. The reported incidence 
rate of pheochromocytomas is approximately 1 case per 100,000 persons, with $10-20 \%$ of cases occurring in children or adolescents. Children have a higher frequency of bilateral tumors than adults $(20 \%$ vs $5-10 \%)$ and a lower incidence of malignancy $(3.5 \%$ vs $3-14 \%)(5,11)$. In our patient the formation was only in left which is a rare finding.

In almost $90 \%$ of the cases tumors are found in the abdomen - suprarenal gland or sympathetic ganglia. The extraadrenal localization, bilateral and multiple tumors are more frequent in children than in adults and with poor prognosis. (9).

Hypertension appears to be uniformly present and is sustained in $80-90 \%$ of affected children at the time of diagnosis. Occasionally, children with sustained hypertension also have paroxysmal episodes. The paroxysms are occasionally precipitated by excitement or a particular physical activity, such as bending over or lifting a heavy object. Such symptoms we had also in our patient.

With high sensitivity are two main methods for the setting of the diagnose: levels of catecholamine in urine and CT scan. (4). In our case because of technical problems we could not test catecholamine in urine and for the setting of the diagnose we trusted only the image tests. Finally it was proved histologicaly .

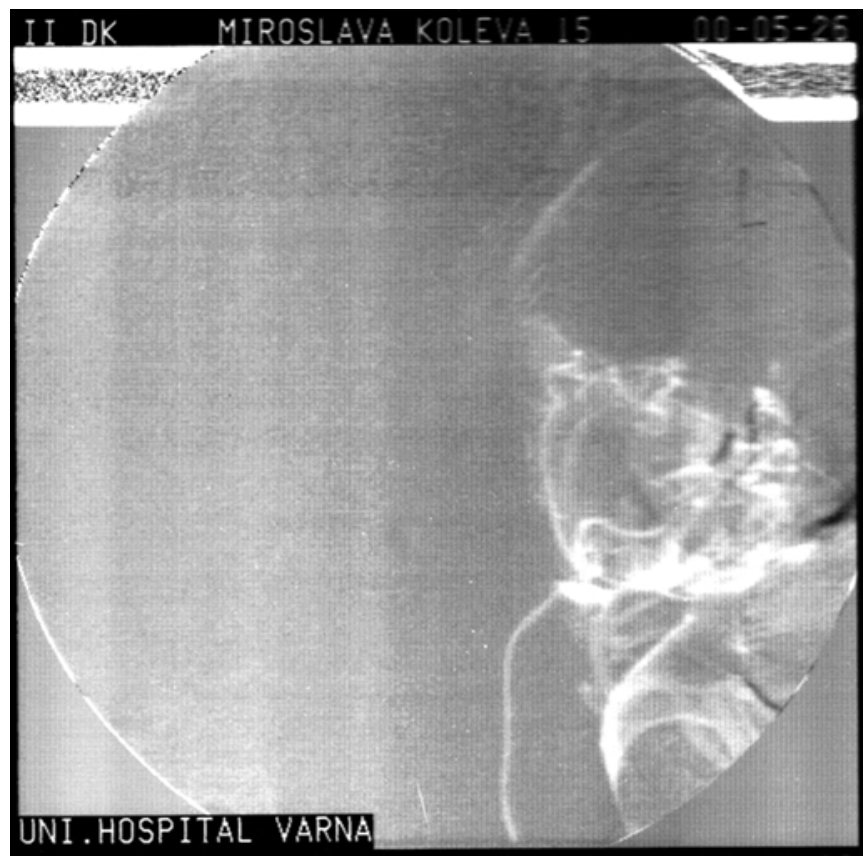

Fig. 1.
The main treatment for the patients is surgical removal of the tumor formation. Schedule surgical removal only after successful pharmacotherapy to block the effects of catecholamine excess. (seizure of the effects of catecholamine excess) (6).

Conclusion: The case is interesting because of the fact, that this is a rare disease in the pediatric practice. Before the admission to the clinic the child had some of the typical symptoms - headache, nausea and vomiting, disorders of vision.

Significant mistake from the position of the good medical practice is the fact that in the presence of such complaints for several months the blood pressure was not measured. The changes in the eye bottom interpreted as neurouveitis are a consequence of high-grade hypertension complicated with hypertonic retinopathia..

In the diagnostic plan we give a high assessment of the complex of image tests, without which the setting of the diagnose was impossible.

And of course not on last place to the successful operative treatment.

The prognosis in our case seems good. The possibility of relapses of the tumor makes obligatory the follow up of the child for the next years.

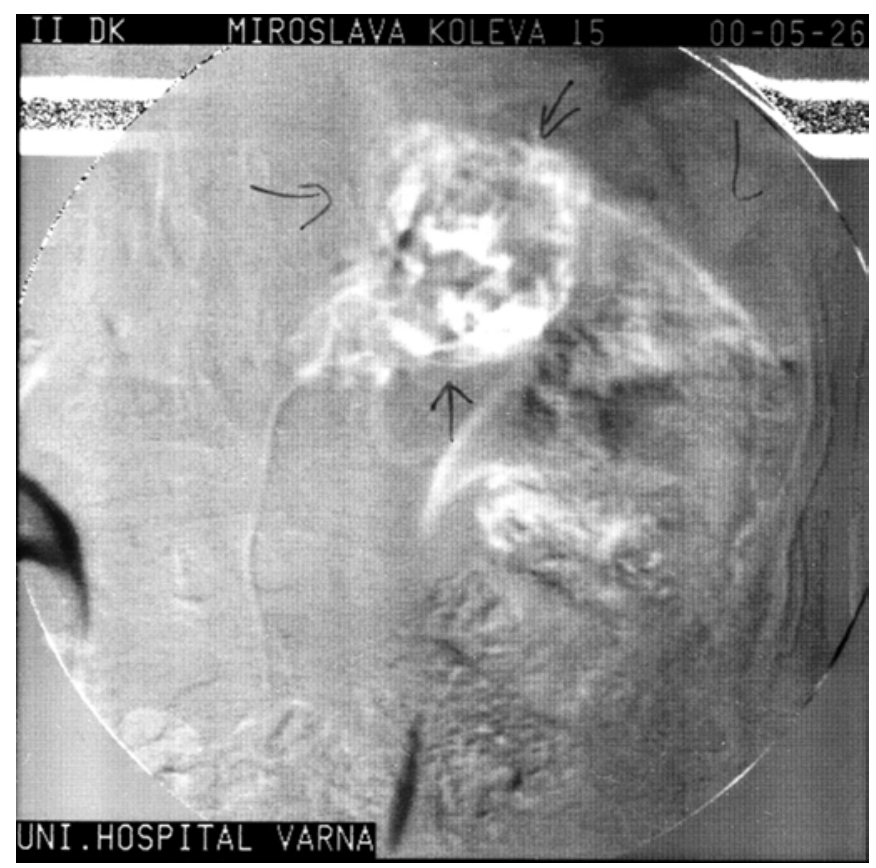

Fig. 2. 




Fig. 3.

\section{BIBLIOGRAPHY:}

1. Рахнева Р., Н. Евтимова, А. Цончева, И. Мендизов. Феохромоцитом в детска възраст с принос на един случай. Педиатрия (С). 1995; 34 (3): 35-37.

2. Цанев Ал., Ж. Желев, С. Зографски и кол. Върху феохромоцитома в детската възраст с принос на един случай. Педиатрия (С). 1973; 12 (5): 325 329.

3. Bhansali A., Rajput R., Behra A., et al. Childhood sporadic pheochromocytoma: clinical profile and outcome in 19 patients. J Pediatr Endocrinol Metab (2006) 19: 749-56.

4. Davidson DF. Elevated urinary dopamine in adults and children. Ann Clin Biochem. May 2005;42(Pt 3):200-7

5. Khorram-Manesh A, Ahlman H,
Nilsson $\mathrm{O}$, et al. Long-term outcome of a large series of patients surgically treated for pheochromocytoma. J Intern Med. Jul 2005; 258(1):55-66.)

6. Kim HY. Experience with surgical excision in childhood pheochromocytoma. J Korean Med Sci.2004; 19(3): 401-6

7. Kohane DS, Ingelfinger JR, Nimkin $\mathrm{K}$, Wu CL. Case records of the Massachusetts General Hospital. Case 162005. A nine-year-old girl with headaches and hypertension. $N$ Engl J Med. May 26 2005;352(21):2223-31

8. Lurbe E., Redon J. Secondary Hypertension in Children and Adolescents. In Secondary Hypertension. Clinical Presentation, Diagnosis and Treatment. Ed. George Mansoon, Humana Press. Totowa,
New Jersey. 2004. 279-303

9. Mittendorf EA, Evans DB, Lee JE, Perrier ND. Pheochromocytoma: advances in genetics, diagnosis, localization, and treatment. Hematol Oncol Clin North Am. 2007;21:509-25

10. National High Blood Pressure Education Program Working Group on High Blood Pressure in Children and Adolescents. The fourth report on the diagnosis, evaluation, and treatment of high blood pressure in children and adolescents. Pediatr 2004. (2 Suppl); 114:555-76.

11. Scholz T, Schulz C, Klose S, Lehnert H. Diagnostic management of benign and malignant pheochromocytoma. Exp Clin Endocrinol Diabetes. 2007; 115 (3): $155-9$
Corresponding Author:

Lachezar Marinov MD,PhD

Department of Pediatrics

Medical University "Prof. Dr Paraskev Stoyanov"

55 Marin Drinov Str., 9000 Varna, Bulgaria

Tel.: +359/899670 525;

E-mail: marrinovs@abv.bg 